Leading Article

\title{
Are Indo-origin people especially susceptible to coronary artery disease?
}

\author{
Naeem Shaukat and David P. de Bono \\ University Department of Cardiology, Glenfield General Hospital, Leicester LE3 9QP, UK
}

There are about 13 million people spread over the globe who can trace their origins back to the Indian subcontinent (Bangladesh, India, Pakistan). The term Indo-origin is used to describe them in this article. The official figure of 1.5 million Indo-origin people settled in the United Kingdom is certainly an underestimate which the 1991 census results may improve. ${ }^{1}$ The majority are still first-generation immigrants who came to Britain in the 1960s and early 1970 s, particularly those arriving via East Africa following political disruption. Other than London, many have settled in the Midlands, West Yorkshire and Greater Manchester.

The first evidence that coronary heart disease (CHD) rates were increased in Indo-origin people abroad came from Singapore in 1959 and was followed by similar findings from South Africa and Trinidad ${ }^{2-4}$ Analysis of national data for England and Wales during the period 1970-1972 demonstrated a standardized mortality ratio for CHD in Indo-origin men and women between the ages of 20-69 of 128 and 129 , respectively (taking the rate of all men and women as being 100$).{ }^{5}$ A $40 \%$ excess of myocardial infarction was found in Indo-origin people compared to whites, in analysis of hospital admission data to National Health Service hospitals for Leicester during 1977 and $1978 .{ }^{6}$ Relative rates of myocardial infarction have been estimated in one study to be nearly four times higher in Indo-origin men compared to Northern European, with infarction occurring at younger age in Indoorigin men.?

Unfortunately, there are no satisfactory population-based data on incidence and prevalence of CHD from the Indian subcontinent. What does seem apparent from the data available is that there is a marked difference in urban-rural rates of CHD. A prevalence of Minnesota coded major Q waves of $0.5 \%$ has been noted in men between the ages of 40-59 from rural Maharashtra in comparison to $3.6 \%$ for men between the ages of 45-64

Correspondence: N. Shaukat, M.R.C.P.

Received: 5 November 1993 in Delhi. ${ }^{8,9}$ The latter figure is similar to the $4 \%$ amongst Indo-origin men between the ages of 40-59 in the recent Southall study. ${ }^{10}$ In other ethnic groups that have migrated to Britain, for instance the Afro-Caribbean and the smaller Chinese communities, mortality from CHD tends to be intermediate between the country of origin's and their adopted country, the usual finding for most diseases among migrant groups. Despite a reduction in CHD mortality in all Western European countries between 1970 and 1985, over the same period there has been a $8 \%$ and $14 \%$ increase in CHD mortality for Indo-origin men and women respectively. ${ }^{11,12}$

It is clear from the above that Indo-origin men and women do have an increased susceptibility to CHD, at least in the UK environment. It should be remembered that words such as South Asian, Asian, Indo-origin are 'umbrella' terms. They do not accurately describe a group of people who are diverse not only in geographical origin, but also in religion, culture and dietary habits. Despite this diversity all Indo-origin subgroups living in this country are at increased risk from $\mathrm{CHD}$, whilst other ethnic groups that have migrated to the UK or US have CHD rates that tend to merge with that of the host country over several generations. In the case of Indo-origin communities settled abroad, mortality rates from CHD diverge from that of the host community within a short period of time and continue to do so over a number of generations. Because of this peculiarity it has been suggested that a genetic rather than an environmental explanation is responsible for the excess rates of CHD seen in Indo-origin people. However, because of their diversity it is very likely that Indo-origin people will be genetically dissimilar. Geographical variation in gene frequency is gradual and not qualitative; populations merge into one another. The complex and polygenetic determination of human phenotype ensures that there are no typical members of groups, and the amount of variation within any ethnic group is larger than between groups. ${ }^{13}$ Some researchers have suggested that the development of CHD in adult life is related to 
retarded fetal and infant growth. ${ }^{14}$ It is certainly plausible that a certain percentage of firstgeneration Indo-origin migrants may have been subject to adverse prenatal and infant environment. However, the same statement could be made for first-generation Afro-Caribbean migrants, who of all ethnic groups in this country have the lowest CHD mortality.

Although our understanding of CHD in the Indo-origin population as in the European population is somewhat limited, it is apparent that the same aetiological mechanisms are involved in both populations. There is little evidence that the fundamental mechanisms of atheroma are different in the Indo-origin and European populations. Comparisons of risk-factor profiles and patterns of coronary disease in Indo-origin and European populations indicate that there is no specific pattern or profile which is exclusive to either, although the population prevalence of certain risk factor patterns is known to vary. ${ }^{15}$ Current evidence seems to suggest that the increased rates of CHD seen in the first-generation Indo-origin migrants are not explained by conventional risk factors for coronary disease. National household survey data in Britain show lower smoking rates in Indo-origin men (apart from Bangladeshi's) than in the general population. ${ }^{16}$ Hypertension does not seem to be a significant factor in explaining the high CHD risk suffered by Indo-origin people. Studies in Trinidad and South Africa have shown that hypertension was less common in Indians compared to Africans and Europeans. ${ }^{17,18}$ In this country blood pressures have been shown to be similar in Indo-origin and Europeans. ${ }^{19}$

The role of cholesterol in CHD aetiology among Indo-origin people has been confused by the consistent finding of lower levels of total plasma cholesterol compared with whites. ${ }^{20,21}$ However, this is primarily due to reduced HDL cholesterol with little difference in LDL levels. Furthermore, there are two recent studies which have found that total cholesterol concentration is closely correlated with extent of coronary atheroma determined at angiography, in both Indo-origin and European populations. ${ }^{15,22}$ These findings suggest that whatever the absolute average levels of cholesterol in Indo-origin communities, a small increase may have long-term effects, so that the threshold at which cholesterol concentrations become important in this population may just be set lower. Dietary comparisons are made difficult by the very varied diet amongst various Indo-origin subgroups. The finding of increased energy and total fat intake in an East African Gujerati Hindu population, on whom most of the dietary surveys have been done cannot therefore be extrapolated for an East African Gujerati Muslim population or any other subgroup for that matter..$^{20}$
Because of the very high prevalence of noninsulin-dependent diabetes in Indo-origin populations (up to $20 \%$ of the Indo-origin population over the age of 40 has diabetes), it has been suggested that the excess of CHD in this community is entirely attributable to non-insulindependent diabetes mellitus. ${ }^{23,24}$ The findings of the St James study in Trinidad, demonstrated, however, that only $13 \%$ of the cross-sectional attributable risk of CHD in the Indo-origin population was due to diabetes. ${ }^{25}$ In addition, Afro-Caribbean people in this country have as high a prevalence of diabetes as the Indo-origin population, yet they have the lowest mortality from CHD of any ethnic group living in the UK.

Even in the absence of overt diabetes, hyperinsulinaemia and insulin resistance have bee shown in prospective European population studies to be an independent risk factor for CHD. ${ }^{26,27}$ In fact it has been suggested that non-insulin-dependent diabetes mellitus may just be one feature of an insulin resistance syndrome ('syndrome $x$ '), whose other features include lipid disturbances and hypertension. ${ }^{28}$ There is increasing evidence to support an increased prevalence of hyperinsulinaemia and increased insulin response to a glucose tolerance test in the Indo-origin population. This finding has been correlated with an increased incidence of central obesity as measured by waist-hip ratio. ${ }^{29}$ However, Afro-Caribbeans in this country and Pima Red Indians in North America seem not to fit in with the insulin resistance hypothesis, in that they both have an increased prevalence of hyperinsulinaemia and diabetes in comparison to the general populations of their respective countries, yet have very low rates of CHD. ${ }^{30}$ An interesting finding from a recent study was that proinsulin and 32-33 split insulin concentrations were increased in all newly diagnosed non-insulin-dependent diabetics in response to a glucose challenge, and that this effect was particularly pronounced in Gujerati subjects in comparison with Afro-Caribbeans and Europeans. ${ }^{31}$

The mechanisms by which insulin leads to increased CHD risk are not clearly known. It has been postulated that there may be a combination of an indirect effect on lipid metabolism and a direct atherogenic effect on the vessel wall. There is also good evidence that insulin concentrations have an effect on haemostatic risk markers for CHD. Insulin concentrations have been shown to be independently related to fibrinogen, von Willebrand factor, factor VIII: $\mathrm{c}$ and, in particular, with plasminogen activator inhibitor- $1 .{ }^{32}$ Restriction of dietary energy intake and physical activity are the only two environmental factors known to alleviate insulin resistance. In a recently completed study on high risk (with a positive family history of CHD) young males, increased fasting insulin concentra- 
tions, waist-hip measurements and a marked reduction in physical activity were found in the young Indo-origin males compared to their European counterparts. In both groups there was a close negative correlation between physical activity and insulin concentrations. ${ }^{33}$

The evidence that second-generation immigrants may already be developing an adverse risk-factor profile for CHD, coupled with the fact that the Indo-origin community is still a relatively young population is an ominous sign. At present only $25 \%$ of this population is over the age of 50 . Data from Leicester indicate that, by the year $2008,50 \%$ of the Indo-origin population there will be over the age of 50 and, if their relative mortality risk from CHD remains at 1.4 compared to the general jopulation, their mortality from CHD will also double over the same period. ${ }^{34}$ There needs to be effective coronary health prevention strategies in the Indo-origin population aimed at all age and sex groups. An increased awareness amongst the Indo-

\section{References}

1. Office of Population Censuses and Surveys. Labour Force Surveys, 1984 (LFS85/1; PP85/3). OPCS, London, 1985.

2. Danaraj, T.J., Acker, M.S., Danaraj, J.W., Ong, W.H. \& Yam, T.B. Ethnic group differences in coronary heart disease in Singapore: an analysis of necropsy records. Am Heart $J$ 1959, 58: 516-526.

3. Wyndham, C.H. Trends with time of cardiovascular mortality in the populations of the RSA for the period 1968-1977. S Afr Med J 1982, 61: 987-993.

4. Miller, G.J., Beckles, G.L.A., Alexis, S.D., Byam, N.T. \& Price, S.G.L. Serum lipoproteins and susceptibility of men of Indian descent to coronary heart disease. The St James survey. Lancet 1982, 2: 200-203.

5. Marmot, M.G., Adelstein, A.M. \& Bulwy, L. Lessons for the study on immigrant mortality. Lancet 1984, i: 1455-1458.

6. Donaldson, L.J. \& Taylor, J.B. Patterns of Asian and non Asian morbidity in hospitals. Br Med J 1983, 286: 949-951.

7. Hughes, L.O., Raval, U. \& Raferty, E.B. First myocardial infarction in Asian and White men. Br Med J 1989, 298: $1345-1350$

8. Jajoo, Un., Kalantri, S.P., Gupta, O.P., Jain, A.P. \& Gupta, $K$. The prevalence of coronary heart disease in a rural population from central India. J Assoc Physicians India 1988, 36: 689-693.

9. Chada, S.L., Radhakrishnan, S., Ramachandran, K., Kaul, U. \& Gopinath, N. Epidemiological study of coronary heart disease in urban population of Dehli. Indian J Med Res 1990, 92: 424-430.

10. McKeigue, P.M., Ferrie, J.E., Pierpoint, T. \& Marmot, M.G. Association of early onset coronary heart disease in South Asian men with glucose intolerance and hyperinsulinemia. Circulation 1993, 87: 152-161.

11. Marmot, M. Coronary heart disease: rise and fall of a modern epidemic. In: Marmot, M. \& Elliot, P. (eds) Coronary Heart Disease Epidemiology from Aetiology to Public Health. Oxford Medical Publications, Oxford, 1992, pp. 3-20.

12. Balarajan, R., Bulusu, L. \& Adelstein, A.M. Patterns of mortality among migrants to England from the Indian subcontinent. Br Med J 1984, 289: 1185-1187.

13. Sheldon, T.A. \& Parker, H. Race and ethnicity in health research. J Pub Health 1992, 14: 104-110. origin population, primary and secondary health care workers should also improve access to care for this high-risk group. ${ }^{35}$ To ensure maximum cooperation these campaigns need to be conducted with sensitivity and have the involvement of the various Indo-origin groups from their inception. Clearly there is a need for further research into the reasons for the excess CHD suffered by the Indoorigin population in this country, but at present our guidelines for primary and secondary prevention in this high-risk group will not differ ostensibly from the rest of the population, that is, to avoid smoking, to prevent obesity, to reduce total energy and fat intake, and possibly the most relevant piece of advice for this group of people is to adopt and maintain some form of regular physical activity.

\section{Acknowledgement}

Both N. Shaukat and D.P. de Bono are supported by the British Heart Foundation.
14. Barker, D.J.P., Winter, P.D., Osmond, C., Margetts, B. \& Simmonds, S.J. Weight in infancy and death from ischaemic heart disease. Lancet 1989, ii: 577-580.

15. Shaukat, N. \& de Bono, D.P. Clinical features, risk factors, and referral delay in British patients of Indian and European origin with angina matched for age and extent of coronary atheroma. Br Med J 1993, 307: 717-719.

16. Balarajan, R. \& Yuen, P. British smoking and drinking habits: variation by country of birth. Commun Med 1986, 8: 237-239.

17. Miller, G.J., Kirkwood, B.R., Beckles, G.L.A., Alexis, S.D., Carson, D.C. \& Byam, N.T.A. Adult male all cause, cardiovascular and cerebrovascular mortality in relation to ethnic group, systolic blood pressure and blood glucose concentration in Trinidad, West Indies. Int J Epidemiol 1988, 17: 62-69.

18. Seedat, Y.K. \& Seedat, M.A. An inter-racial study of the prevalance of hypertension in an urban South African population. Trans $R$ Soc Trop Med Hyg 1982, 76: 62-71.

19. Cruickshank, J.K., Jackson, S.H.D. \& Beevers, G. Similarity of blood pressure in Blacks, whites and Asians in Britain. Hypertension 1985, 3: 365-371.

20. Miller, G.J., Kotecha, S., Wilkinson, W.H. et al. Comparison of dietary and other characteristics for coronary heart disease in men of Indian, West Indian and European descent in London. Atherosclerosis 1988, 70: 63-72.

21. McKeigue, P.M., Marmot, M.G., Adelstein, A.N. et al. Diet and risk factors for coronary heart disease in northwest London. Lancet 1985, ii: 1086-1089.

22. Hughes, L.O., Wojceiechowski, Ap. \& Raferty, E.B. Relationship between plasma cholesterol and coronary artery disease in Asians. Atherosclerosis 1990, 83: 15-20.

23. Woods, K., Samanta, A. \& Burden, A.C. Diabetes mellitus as a risk factor for acute myocardial infarction in Asians and Europeans. Br Heart J 1989, 62: 118-122.

24. Padhani, A. \& Dandona, P. Diabetes and coronary heart disease in north London Asians. Lancet 1986, i: 213-214.

25. Beckles, G.L.A., Miller, G.J., Kirkwood, R.B. et al. High total cardiovascular disease mortality in adults of Indian descent in Trinidad, unexplained by major coronary risk factors. Lancet 1986, i: 1298-1301. 
26. Eschwege, E., Richard, J.L., Thibult, N., Ducimetiere, P., Warnet, J.M. \& Claude, J.R. Coronary heart disease mortality in relation with diabetes, blood glucose and plasma insulin levels: the Paris Prospective Study, ten years later. Horm Metab Res 1985, 15: 41-46.

27. Pyorala, K., Savolainen, E., Kaukola, S. \& Haapakoski, J Plasma insulin as coronary heart disease risk factor: relationship to other risk factors and predictive value during 9.5 year follow up of Helsinki Policeman Study population. Acta Med Scand 1985, 701: 38-52.

28. Reaven, G.M. Role of insulin resistance in human disease Diabetes 1988, 37: 1595-1607.

29. McKeigue, P.M., Shah, B. \& Marmot, M.G. Relation of central obesity and insulin resistance with high diabetes prevalance and cardiovascular risk in south Asians. Lancet 1991, 337: 382-386.

30. Aronoff, S.L., Bennett, P.H., Gorden, P., Rushforth, N. \& Miller, M. Unexplained hyperinsulinemia in normal and prediabetic Pima Indians compared with normal Caucasians. An example of racial differences in insulin secretion. Diabetes 1977, 26: 827-840.
31. Cruickshank, J.K., Clark, P.M., Riste, L.K., Cooper, J. \& Hales, C.N. Insulin deficiency but excess proinsulin secretion during glucose challenge of British AfroCaribbean and Indo-origin populations with high rates of diabetes. Diabetic Med 1993, 10: 524.

32. Juhan Vague, I., Thompson, S.G. \& Jespersen, J. Involvement of the Hemostatic system in the insulin resistance syndrome. Arteriosclerosis Thrombosis (in press).

33. Shaukat, N. \& de Bono, D.P. Physical activity and insulin concentrations in Indo-origin and Northern European young adult males with a positive family history of coronary heart disease. (Submitted for publication).

34. Lowy, A.G.J., Woods, K.L. \& Botha, J.L. The effects of demographic shift on CHD mortality in a large migrant population at high risk. J Pub Health Med 1991, 13: 276-280.

35. Shaukat, N. \& Cruickshank, J.C. Coronary heart disease in Indo-origin people, is access to care an issue. In: Hopkins, A. (ed.) Access to Health Care for Ethnic Minorities Royal College of Physicians, London, 1993, pp. 133-144. 